\title{
PATTERN AND FACTORS ASSOCIATED WITH HOME ACCIDENTS AMONG UNDER-FIVE CHILDREN AND ITS CARE SEEKING BEHAVIOR IN SELECTED RURAL COMMUNITIES OF KOTA SAMARAHAN DISTRICT, SARAWAK, MALAYSIA
}

\author{
LIM JYH HANN ${ }^{1}$, MD MIZANUR RAHMAN ${ }^{1}$
}

\begin{abstract}
Background: Home may beconsidered a place toescape the dangers of theoutside world. Children have the highest risk for home injury and accidents. Considering this view, this study was aimed to describe the pattern of home accidents among the under-five children in selected villagesin Kota Samarahandistrict andto determine their care-seeking behavior.

Materials and Methods: This was a cross-sectional study conducted in four villages in Kota Samarahan district. A total of 917 households were visited. Among them, 261 households were having under five children. Out of 261 households, 248 had completed the interview with the response rate of $95 \%$. Data was collected from caregivers of under-five children by face to face interview by interviewer-administered questionnaire. Data entry and analysis was done by IBM SPSS version 22.0. A p-value less than 0.05 wasconsidered as statistically significant.

Results: The prevalence of home accident was $68.1 \%$ in thelast six months. Two-fifths (40.3\%) of the households had at least one incidence of home accidents. The most common home accidents were fall (56.9\%) followed by cut/ wound (16.9\%) and struck by an object (10.5\%). Logistic regression analysis revealed that age, marital status and household income appeared to be important predictors of home accidents among under-five children $(p<0.05)$. More than half of the respondents took home treatment for accidents such as fall, cut/ wound, struck by an object and insect bites. While all who suffered from severe home accidents such as poisoning, suffocation and vehicle accidents would visit the nearest healthcare facilities for treatment.
\end{abstract}

Conclusion and Recommendation: A comprehensive and preventive program could be implemented involving the vulnerable segments of the population and emphasise on most common home accidents as in the study findings.

Keywords: Care seeking behaviour, Home accident, Knowledge, Prevalence, Under-five child, Sarawak.

\section{Introduction}

Home accidents are considered one of the new epidemics in the era of 21 st century, though thehome is regarded as the safest place for most people. ${ }^{1}$ World Health Organization (WHO) and the Global Burden of Diseases Study (GBS) has suggested that unintentional accidents account for 3.9 million deaths worldwide by indirect estimation which is $10 \%{ }^{2}$ Majority of the deaths, in which about $90 \%$ occur in low and middle-income countries. ${ }^{3}$ Despite home accidents' concern is not shared by the general population, home accidents are one of the leading cause of death, in addition, it is a major reason for hospitalisation that could lead to long-term

Faculty of Medicine and Health Sciences, Universiti Malaysia Sarawak

Address of Correspondence: Dr. Md Mizanur Rahman, Professor, Faculty of Medicine and Health Sciences, Universiti Malaysia Sarawak, Email: rmmizanur@unimas.my rmizanur1958@gmail.com

Bangladesh J Medicine 2017; 28 : 58-62 
disability. ${ }^{4}$ In Malaysia, National Health Morbidity Survey (NHMS) reported that home accidents are second highest unintentional injury after road traffic accidents, and had accounted for $2.5 \%$ prevalence among under-five children. ${ }^{5}$ In reality, the state wise statistics on home accidents is limited. The objective of this study is to determine the pattern of home accidents, factors associated with home accidents and its care seeking behaviour among the caregivers under five children in selected communities of Kota Samarahan district, Sarawak.

\section{Materials and methods}

Study design and sampling procedure

This was a cross-sectional community-based study conducted in selected four villages of Kota Samarahan district, Sarawak, Malaysia. The study population consisted of parents / caregivers, who aged 18 years and above, irrespective of gender, and were staying with at least one or more under five children. Baseline data on the list of households and location of the household map of the villages were obtained from Ketua Kampung (Village Headman) before the research started. A total of 917 households were visited in the four villages. Among these, 261 households (28.5\%) had at least one under-five years' child, while the remaining $656(71.5 \%)$ did not have any under-five children. Within the 261 households, there were 248 households which cooperated and participated in the study (95\%). On the other hand, there were 13 households (5\%) which declined and refused to participate in the study due to various reasons, even after three times repeated visit within four months of data collection period.

\section{Data collection instruments and data collection procedure}

A structured questionnaire was used for data collection. The questionnaire consists of sociodemographic characteristics, knowledge on home accidents, the pattern of accidents, care seeking behavior. The data on socio-demographic characteristics were age, gender, religion, ethnicity, marital status, education level, occupation, number of family members, number of under-five children and household income. To assess the knowledge on home accidents a series of questions asked relevant to the home accidents. The response may be 'yes', 'no' or 'do not know'. As for the pattern of accidents, respondents were asked regarding home accidents which took place in the last six months. If there was accident or accidents happened in the last six months, the respondents were further asked about the care seeking behaviour, which couldvisithealth care facilities, first aid, home remedy, counsel by relatives, traditional methods or others. After an interview, respondents were being requested to allow the interviewer to visit inside houses to observe the safety measure taken against home accidents. A checklist was used to identify safety measures which were present at home as well as unsafe environment characteristic which can lead to home accidents. The eligible respondents in the rural community that fulfil the criteria were interviewed using aninterviewer-administered questionnaire for the data collection. The questionnaire was adapted to Malay language using back-to-back translation, where it involved two steps. First, the original questionnaire was translated into Malay. After the process completed, the questions were translated back into English. There were no items that appear to be discrepant to the meaning of the original item after the translation. Finally, it was pre-tested in the non-sample area. All the data was collected by the researcher himself.

\section{Data analysis}

The collected data was coded and analysed using Statistical Package for Social Science, version 22.0 (IBM SPSS, 2012). ${ }^{6}$ Descriptive statistics includes frequency, percentage, mean and standard deviation was calculated. For inferential statistics, Chi-square test of independence was done to find the significant association between qualitative variables. Finally, a binary logistic regression analysis was done to determine the factors associated with home accidents.

\section{Ethical Considerations}

Ethical approval for this study was obtained from the Ethics Committee of Universiti Malaysia Sarawak (UNIMAS) [Ref. no. UNIMAS/NC-21.02/03-02(88)]. Ethical approval for this study was also obtained from Medical Research and Ethics Committee (MREC), Ministry of Health (MOH), Malaysia [ Ref. no. (05)KKM/NIHSEC/p16-1063]. All respondents were briefed about the objectives of the study and a written informed consent was obtained before data collection.

\section{Results}

\section{Sociodemographic characteristics}

The mean (SD) age of the respondents was 36.73(12.4) years with minimum age 18 and maximum age was 72 years. Two-thirds of the respondents were female (65.7\%).Majority of the respondents were Muslim (77\%). Out of 248 respondents, $72.2 \%$ were Malays followed by Iban (17.7\%) and the remaining were others (Melanau, Bidayuh etc.). Most of the 
respondents were married (90\%). More than half of the respondents had secondary school level of education $(54.8 \%)$ followed by primary level of education (25\%), diploma and above (14.5\%). The median family size was 6 with a minimum of 3 and maximum of 20 members. About half $(47.6 \%)$ of the respondents were housewife followed by one-fifth $(19 \%)$ who were working as private employees. About one-tenth $(8.5 \%)$ of the respondents had own business, however, there was $13.1 \%$ of respondents were unemployed when the interview was carried out. The median income for the household was MYR 1500 with minimum MYR 500 and maximum MYR 10000. About three-fifths (57.7\%) of the family had one underfive child, followed by one-third (35.1\%) respondents who had two children (Table 1).

Table-I

Socio-demographic characteristics of the respondents

\begin{tabular}{lcc}
\multicolumn{3}{c}{$(n=248)$} \\
Characteristics & $\begin{array}{c}\text { Frequency/ } \\
\text { Mean (SD) }\end{array}$ & $(\%)$ \\
\hline Age in years (SD) & $36.73(12.4)$ & \\
Gender & & \\
Male & 85 & 34.3 \\
Female & 163 & 65.7
\end{tabular}

Religion

Islam

77.0

Christianity

Ethnicity

Malay

Iban

Others (Bidayuh, Melanau etc.)

Marital status

Single

Married

Level of education

No formal education

Primary school

Secondary school

Diploma and above

Occupation

Unemployed

Own business

Government employee

118

Median Family size (min, max) $6(3,20)$ Median income (min, $\max$ ) MYR 1500 $(500,10000)$

Number of under 5 children $1(1,6)$

\section{Pattern of Home accidents}

Out of 248 households, 68.1\% had ahistory of home accidents. It was found that $40.3 \%$ households had at least one incidence of home accidents and 22,6\% had two incidences of home accidents and $4 \%$ had three or more occurrences. Highest percentages of households had ahistory of fall (83.4\%) followed by cut injury (24.9\%), struck by anobject (15.4\%), insect sting/ bite (12.4\%). The history of animal bites, burn, chocking was minimal. A more severe home accident such as poisoning, suffocation, electrical accidents and vehicle accidents around the house compound was rarely reported (Figure 1).

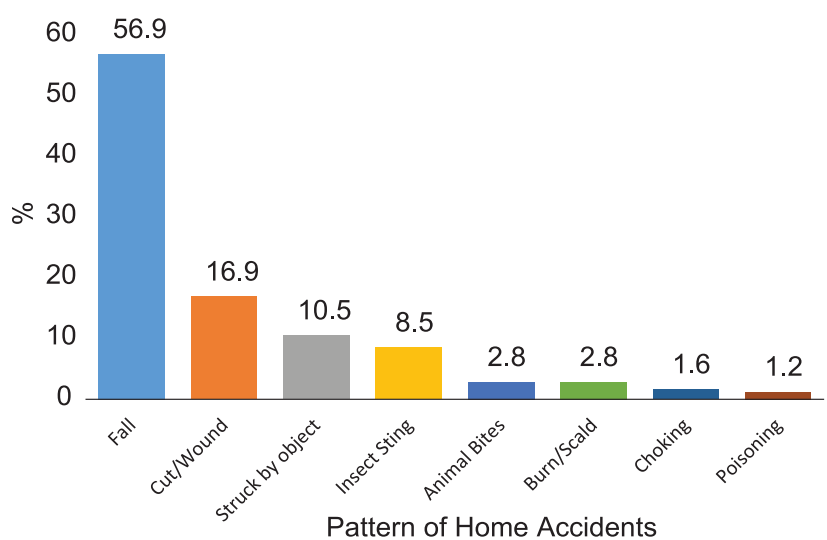

Fig.-1: Pattern of home accidents ( $n=248$ )

(Percentage exceeded 100 due to multiple responses)

Pattern of care seeking behaviour: Table 2 shows the pattern of care seeking behaviour for home accidents among the respondents. Majority of the respondents took home treatment for accidents such as fall $(61 \%)$, cut injury $(66.7 \%)$, struck by objects $(76.9 \%)$, insect bite $(71.4 \%)$, animal bites $(42.9 \%)$. However, in thecase of poisoning, suffocation, vehicle accidents as well as burn or scalds, all the respondents did bring their children to the nearest healthcare facilities for treatment (100\%). Some of the respondents reported to give first aid for animal bites $(42.9 \%)$ and choking (50\%) when the accident happened. As for the traditional method of treatment, there were only few who suffered from fall, insect sting, burn/scald and choking chose institutional treatment.

\section{Factors associated with home accidents: binary logistic regression analysis}

To determine the factors affecting home accidents, a binary logistic regression was done. The dependent variable, 'home accident', was dichotomized and dummy coded into Yes (1) and No (0). The variables which were statistically significant in Chi-square test were included into the logistic regression model. The independent variables such as age, marital status, level of education and monthly household income were found to be significant in the Chi-square Test. Table 3 shows the results of this analysis. The full model containing all the predictors was statistically 
significant [Ç2 $(\mathrm{df}, \mathrm{N}=248)=36.466(10), \mathrm{p}<0.001]$ indicating that the model could distinguish between who had a history of home accident or not in the last 6 months. The model explained between 13.7\% (Cox and Snell R square) and 19.2\% (Nagelkerke R squared) of the variance of home accidents and was correctly classified in $72.6 \%$ of the cases. The goodness of fit indices was not statistically significant $(p>0.05)$, which indicated a well-fitted model and did not violate the assumption of homogeneity. During the analysis, three of the independent variables made a unique contribution to the model $(p<0.05)$, namely age, marital status and monthly household income. However, the level of education was found to be not statistically significant $(p>0.05)$. The caregivers / respondents with age group 25-34 years had an odds ratio of 5.319 (95\% CI: 1.644, 17.212) and that of age group 35-44 years had an odds ratio 4.203 (95\% CI: $1.373,12.872)$. This indicated that respondent's age group 25-34 years 5.319 times likely to have home accidents and 4.203 times in the age group 35-44 years. Similarly, home accidents were 4.674 times likely to have when caregivers are single compared to currently married (Adj OR=4.674; 95\% CI: 1.118, 19.543). The home accident was 2.936 times higher among the respondents' monthly income less than MYR 1000 (Adj OR=2.936; 95\% CI: 1.139, 7.564) than the reference category.

Table-II

Pattern of treatment received after home accidents

\begin{tabular}{|c|c|c|c|c|c|}
\hline \multirow[t]{2}{*}{ Home accidents } & \multirow[t]{2}{*}{$\mathrm{n}$} & \multicolumn{4}{|c|}{ Pattern of treatment } \\
\hline & & Health Facilities & First Aid & Home remedy & Traditional \\
\hline$\overline{\text { Fall }}$ & 141 & 12.1 & 12.1 & 61.0 & 14.9 \\
\hline Cut/Wound & 42 & 28.6 & 4.8 & 66.7 & - \\
\hline Struck by object & 26 & 7.7 & 15.4 & 76.9 & - \\
\hline Insect Sting & 21 & - & - & 71.4 & 28.6 \\
\hline Animal Bites & 7 & 14.3 & 42.9 & 42.9 & \\
\hline Burn/Scald & 7 & 57.1 & - & 14.3 & 28.6 \\
\hline Choking & 4 & - & 50.0 & 25.0 & 25.0 \\
\hline Poisoning & 3 & 100.0 & - & - & - \\
\hline Suffocation & 2 & 100.0 & - & - & - \\
\hline Electric accident & 1 & - & - & 100.0 & - \\
\hline Vehicle accident & 1 & 100.0 & - & - & - \\
\hline
\end{tabular}

Table-III

Factors affecting home accidents among under five children: binary logistic regression analysis

\begin{tabular}{|c|c|c|c|c|}
\hline \multirow[t]{2}{*}{$\overline{\text { Variables }}$} & \multirow[t]{2}{*}{2} & \multirow[t]{2}{*}{ Adj. OR } & \multicolumn{2}{|c|}{$95 \% \mathrm{CI}$} \\
\hline & & & Lower Limit & Upper Limit \\
\hline \multicolumn{5}{|l|}{ Age in years } \\
\hline$<25$ & 0.700 & 2.013 & 0.489 & 8.279 \\
\hline $25-34$ & $1.671^{* *}$ & 5.319 & 1.644 & 17.212 \\
\hline $35-44$ & $1.436^{*}$ & 4.203 & 1.373 & 12.872 \\
\hline $45-54$ & 0.927 & 2.527 & 0.772 & 8.274 \\
\hline e"55 (RC) & & 1 & & \\
\hline \multicolumn{5}{|l|}{ Marital Status } \\
\hline Single & $1.542 *$ & 4.674 & 1.118 & 19.543 \\
\hline Married (RC) & & 1 & & \\
\hline \multicolumn{5}{|l|}{ Level of education } \\
\hline No formal education (RC) & & 1 & & \\
\hline Primary school & 1.025 & 2.788 & 0.713 & 10.909 \\
\hline Secondary school & 0.533 & 1.704 & 0.389 & 7.454 \\
\hline College/ Diploma & 1.153 & 3.166 & 0.536 & 18.701 \\
\hline \multicolumn{5}{|c|}{ Household income per month } \\
\hline$<1000$ & $1.077^{*}$ & 2.936 & 1.139 & 7.564 \\
\hline 1000-1999 & 0.189 & 1.208 & 0.624 & 2.338 \\
\hline$\geq 2000(\mathrm{RC})$ & & 1 & & \\
\hline Constant & -1.499 & .223 & & \\
\hline $\mathrm{n}$ & 248 & & & \\
\hline Model Chi square (df) & $36.466(10)^{* * *}$ & & & \\
\hline Goodness of fit & $\mathrm{p}>0.05$ & & & \\
\hline Cox \& Snell R Square & 0.137 & & & \\
\hline Nagelkerke R Square & 0.192 & & & \\
\hline
\end{tabular}

Adj. $\mathrm{OR}=$ Adjusted odds ratio; $\mathrm{RC}=$ Reference Category 


\section{Discussion}

The home accidents arecommon phenomenon among the under five children that are often neglected. The prevalence of home accident in this study was $68.1 \%$ over the past six months.This is consistent to Pakistan, where $85 \%$ of accidents were reported at home. ${ }^{7}$ In contrast, only $2.5 \%$ of overall prevalence of home accidents was reported in Malaysia. ${ }^{5}$ Fall was the highest form of thehome accident reported in this study. This is understood that children can explore and new things they learn during development, put them more prone to home accidents. This finding also supported by Department of Statistics, Ministry of Health, Malaysia. ${ }^{8}$ The action after a home accident can be seen from the pattern of care seeking behaviour. Majority of the respondents prefer home remedy for less severe cases, however, in general, $46.9 \%$ of the population prefer to seek treatment at the nearest healthcare facilities when the home accidents occurred. ${ }^{8}$ Younger caregivers found to be one of the factors affecting home accidents. This is due to the fact that caregivers in this group were new parents and inexperience in taking care of children. Besides that, low household income was found to be statistically significant in influencing home accidents. There might be the possible reason that parents or caregivers working long hours and had less time to spend at home and as a result neglect the activities that their children engaged with. Lack of awareness of risks and home accidents are also one of the examples where lowincome group tends to have lower education level. On the other hand, this study reported that higher education levels also lead to the higher occurrence of home accidents. Although the caregivers had good knowledge score, yet the prevalence was also high (Table not was shown). This is understood that knowledge doesn't always reflect on theaction. Parents chose to be ignorant to what good practice to prevent home accidents that they know. Another reason was that highly educated mothers tend to be employed and absent from home for a big amount of time during the day, hence, less interest and time to learn about safety preventive measures. ${ }^{9}$ A great number of parents prefer home remedy when home accidents happened, especially for less severe cases. However, it is not recommended as parents might underestimate the seriousness of the accident and children risk of getting the right treatment in the early safe. Traditional methods of treatment also remain important in the villages, which correlates in this rural communities.

\section{Limitations}

This study has some limitations that need to be addressed. First, this may not be the representative of the population in Sarawak, because Kota Samarahan district was selected as the sampling area. In addition is the selection of villages and participants in the village setting. There may be a selection bias as the majority of the respondents were female, mainly housewives. Mostly data collection took part during working days, where most male respondents were away from work. Recall bias is also one of the limitations, where respondents were asked to remember home accidents happened for the past six months.

\section{Conclusion}

The prevalence of a history of home accidents over the past six months in Kota Samarahan district was higher compared to other countries. There was at least one occurrence of home accidents in the prevalence of this study. Single and ahousehold income less than RM1000 appeared to be important predictors of home accidents among under-five children. As for the pattern of care seeking behaviour, majority of the respondents prefer home remedy for less severe cases; whilst theyvisit the nearest healthcare facilities was the first choice for severe accidents. A strategic health promotion intervention program, focusing the falls would be recommended as fall is the highest occurrence of a home accident. First aid care should also be given emphasis as it was among the lowest pattern of care seek behaviour, largely due to the inexperience of first aid knowledge. Knowledge of risk factors of the home accident remains a crucial factor in its prevention.

\section{Acknowledgements}

We are thankful and appreciate all the help from the Ketua-ketua Kampungs (Village Heads) who were involved, provided their kind assistance as well as cooperation. We are indebted to the villagers who had participated in this study.

\section{Conflict of interest}

The authors declare that they have no competing interests.

\section{Authors Contribution}

LJH and MMR designed the study. LJH was responsible for data collection, data entry and drafting the manuscript. MMR involved in data analysis and manuscript editing. All authors read and approved the final manuscript. 